\title{
RECENT DEVELOPMENTS IN ABRASIVE HYBRID MANUFACTURING PROCESSES
}

\author{
Adam Ruszaj, Sebastian Skoczypiec, Dominik Wyszyński \\ Cracow University of Technology, Institute of Production Engineering, Poland \\ Corresponding author: \\ Sebastian Skoczypiec \\ Cracow University of Technology \\ Institute of Production Engineering \\ al. Jana Pawta II 37, 31-864 Kraków, Poland \\ phone: +4812 374-37-49 \\ e-mail:skoczypiec@mech.pk.edu.pl
}

Received: 30 October 2015

Accepted: 23 December 2016

\begin{abstract}
Recent dynamic development of abrasive hybrid manufacturing processes results from application of a new difficult for machining materials and improvement of technological indicators of manufacturing processes already applied in practice. This tendency also occurs in abrasive machining processes which are often supported by ultrasonic vibrations, electrochemical dissolution or by electrical discharges. In the paper we present the review of new results of investigations and new practical applications of Abrasive Electrodischarge (AEDM) and Electrochemical (AECM) Machining.
\end{abstract}

KEYWORDS

hybrid manufacturing process, electrochemical, electrodischarge, abrasive, machining, grinding.

\section{Introduction}

Development of manufacturing processes is stimulated by demands of designers of modern devices for space, weapon, aviation, automotive, medical and households goods industry. For example, medical industry requires adequate equipment, tools (i.e. surgical ones) and implants made of biocompatible materials and characterized by resistance to body fluids and harmlessness to human body. Modern structures should be made of new, optimally selected materials which would ensure their proper application features (durability, reliability, functionality, modern design, low production and exploitation costs). Designers should also use to advantage in their work recent scientific developments, especially in the fields of micro and nanotechnology. Achievements in this field enable, among others, miniaturization of parts and material and energy saving. To cope with above mentioned requirements all manufacturing methods are intensively developed, especially hybrid ones, where part shaping is realized by simultaneous use of different machining mechanisms and (or) different forms of energy $[1,2]$. Hybrid manufacturing processes are differently defined by researchers and industrial engineers. The processes of controlled combination of appearing effects, which conventionally are induced by separate operations (machining and shaping, or machining and changing surface layer properties that are not directly connected with machining processes) are also classified as hybrid processes. For example combination of allowance removal assisted with quenching - in order to generate adequate amount of heat, deeper grinding depth (e.g. $0.5 \mathrm{~mm}$ ) and lower feed rate are applied. After surface cooling with working liquid the hardness can reach up to $800 \mathrm{HV}$, and $650 \mathrm{HV}$ at depth of $300 \mu \mathrm{m}$ [2]. Among hybrid methods particularly important roles are played by unconventional finishing processes like electrochemical, electro discharge and abrasive machining. Sequential manufacturing becomes more and more important e.g., electrochemical finishing, electro discharge and electrochemically abrasive machining applied after rough electro discharge machining [3, 4]. Sequential methods are complementary to hybrid methods by means of rationalization of manufacturing processes. This work is dedicated to hybrid processes, where the allowance is removed by means 
of electric discharge, electrochemical dissolution and mechanical impact of abrasive grains.

Material science develops dynamically and offers new materials of special properties. Their rational industrial application is possible only after development of effective shaping methods. Dynamic development of space, aviation, automotive and electronic or house hold industry sets new demands on accuracy and surface quality of the machined parts. Taking into account above mentioned facts production processes start to deal with hybrid machining processes. These processes simultaneously and reliably allow to take advantage on interaction of various mechanisms of the process or (and) various sources of energy. That has serious positive impact on technological factors.

Abrasive machining is well settled in industrial processes and thus there is continuous effort to improve their effectiveness by decreasing abrasive forces, increasing machining efficiency, decreasing the temperature, improving shape accuracy and machined surface micro structure (decreasing roughness) as well as surface layer quality (e.g. less heat defects in machined surface). Intensive research has been carried out with the aim of supporting various grinding processes by ultrasonic vibrations. Especially for machining of special materials, alloys, composites and ceramics [5-12]. In majority of cases presented in the literature above mentioned effects were reached by application of ultrasonic vibrations (usually of amplitudes from 1 to $15 \mu \mathrm{m}$ and frequencies from 10 up to $80 \mathrm{kHz}$ which were realized by the tool or machined part). Impact of the vibrations on grinding results was always positive. Another important direction of hybrid abrasive processes development is grinding assisted by cryogenic cooling $(T<$ $-150^{\circ} \mathrm{C}$ ), that is also assumed as hybrid process (so called Media Assisted Machining) [13-15]. Low efficiency of conventional cooling liquids and their negative impact on natural environment led to application of liquid nitrogen as an alternative cooler, that substantially decreases grinding forces, temperature in grinding area and ensures better machined surface quality (reducing Ra and heat defects) and moreover is completely harmless for the natural environment.

Some research has also been conducted on chemical, electrochemical or electro discharge intensification of abrasive machining. Negative impact of applied working liquids (especially electrolytes) on work and natural environment decreased scientific interest in this method. However some advantages of electrochemical and electro discharge intensification of abrasive processes are still important for space, aviation and defense industries and production of
MEMS (Micro-Electro-Mechanical-Systems). Original examples presenting application of electrochemical intensification of grinding in finishing operations has been presented below.

\section{Characterization of hybrid electro-discharge abrasive machining processes}

Hybrid processes of electro discharge-abrasive machining are based on simultaneous and controlled interaction of electric discharges (material removal by heating, melting, evaporating and solidification) and mechanical impact of abrasive grains. The latter can be performed by using bonded abrasive (grinding wheels, whetstones, strings, tapes, brushes containing abrasive) and loose not bonded abrasive mixed with dielectric fluid. In case of loose abrasive grains they flow with dielectric fluid and hit the machined material. Moreover, when abrasive grain is in an electric discharge (explosion) area they gain additive kinetic energy improving grinding process. If additionally ultrasonic vibrations of the electrode tool, machined part or dielectric fluid are applied, cavitation phenomena can occur when some threshold is reached. In cavitation area forming, growth and violent implosion of gas bubbles occurs. As a result, high pressure $\left(\sim 1000 \mathrm{kG} / \mathrm{cm}^{2}\right)$ and high temperature $(\sim 5000 \mathrm{~K})$ and temperature change ratio appear locally and can reach up $10^{7} \mathrm{~K} / \mathrm{s}$. In other words, cavitation seriously changes physical conditions in machining area [16].

Independently from mechanical impact of abrasive grains on machined material during electric discharge phenomena like heating, melting, evaporating and solidification of machined material are observed in the machining area. Heated material is more prone to deformations by hitting abrasive grains and melted material is more efficiently removed (pressed out) from an erosion craters by passing by dielectric liquid, especially when cavitation appears (cavitation erosion) $[17,18]$. However, in electrodischarge machining in mixture of dielectric liquid and abrasive grains the contribution of mechanical impact of abrasive grain is low due to their low kinetic energy (grains are very light) coming from the dielectric flow or occurring cavitation phenomena. Their impact on allowance removal is in that case also usually negligible.

What appears important is the impact of powder (also abrasive grains) on electrical field distribution in an interelectrode gap as it causes change in discharge energy sharing between electrode tool and machined part [17-19]. Based on analysis of the re- 
sults, one can expect that more energy is delivered to machined part than to electrode tool. That is why, after adding powder to dielectric fluid interelectrode gap thickness and crater diameter size are increasing, while crater depth (but not volume) decreases. It causes improvement of machining efficiency and surface quality and minimizes electrode tool wear. Moreover if proper powder is applied (e.g. abrasive $\mathrm{TiC}$ of $3200 \mathrm{HV}$ and grain size $10 \mu \mathrm{m}$ ) it becomes at least partially melted into surface layer of the machined part (mean temperature in discharge channel can reach even $12000 \mathrm{~K}$ ). This positively changes surface properties (e.g. higher hardness) but also reduces white layer and improves surface wear resistivity etc.

Therefore, due to above mentioned facts, the electrodischarge machining assisted by loose abrasive grain is not used in practice. Because introduction of powder material to dielectric fluid in other way and more seriously improves machining process than mechanical impact of abrasive grains. Processes of grinding and electro discharge - abrasive cutting, where abrasive machining impact is relevant, and process can be used in practice will be characterized below.

\section{Abrasive electro discharge grinding (AEDG)}

One of the most effective ways to improve manufacturing processes' efficiency is combining various physical and chemical processes having impact on machined material in one hybrid process. Pertinence of this statement is also proved in abrasive electro discharge processes [20-22]. In AEDG synergy effect is represented by higher efficiency and lower grinding wheel wear (when such difficult to machine materials like PCD, technical ceramics, sintered carbides and composite materials are processed). Electrical discharge causes melting of some part of the machined material. Melted material has decreased mechanical properties, as a consequence forces required to remove the material are lower and tool wear decreases. Moreover, in this process self-sharpening of the grinding can be observed due to electrical discharge when some part of the energy is passed to the tool causing melting and evaporation of the grinding wheel binder, what results in revealing new abrasive grains. The mentioned advantages and effects are confirmed in recent research concerning machining of such materials as nickel alloys, technical ceramics, sintered carbides and metal matrix composites [21-23].

The mechanism of material removal in AEDG is complicated due to mechanical and thermal inter- dependence of energy leading to allowance removal [21-23]. In case of grinding, the metal matrix grinding wheel is connected to the pulse generator cathode (Fig. 1). Due to new practical applications of this process some works aiming at modelling and its optimization are carried out.

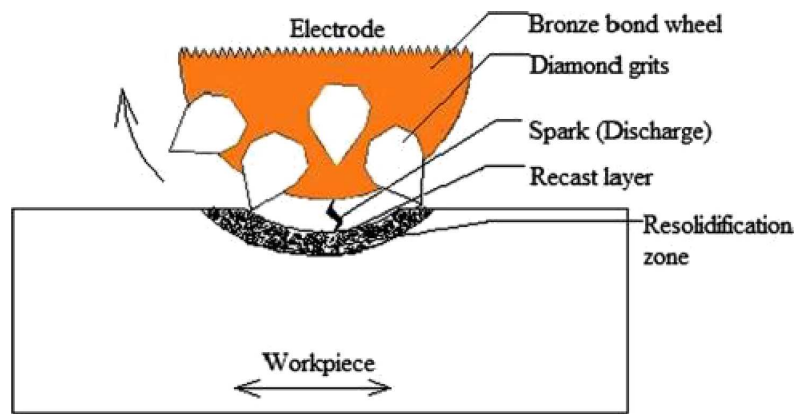

Fig. 1. Scheme of material removal in AEDG process using bronze bond diamond grinding wheel [21].

A mathematical model was prepared. The model was built on basic rules of allowance removal by EDM and conventional grinding process. It was proven that dominant role in allowance removal plays energy of electrical discharge. Results of calculations according to this model do not differ from empirical results more than $2.75 \%$. From results of carried research one can conclude that abrasive grains remove from machined part layer of recast material [21] (Fig. 1).

\section{Technical ceramics $\mathrm{Al}_{2} \mathrm{O}_{3}-\mathrm{SiCw}-\mathrm{TiC}$ grinding}

The research presented in [21] was carried out for ceramic electrically conductive material $\mathrm{Al}_{2} \mathrm{O}_{3}{ }^{-}$ $\mathrm{SiCw}-\mathrm{TiC}$. The machined material had following properties: hardness $2400 \mathrm{HV}$, thermal conductivity $63 \mathrm{~W} / \mathrm{mK}$ and electrical resistivity $0.009 \Omega \mathrm{cm}$. The grinding wheel was made of bronze binder and diamond grains of granularity 800. Grinding wheel was of $100 \mathrm{~mm}$ diameter and $20 \mathrm{~mm}$ width. As a dielectric fluid kerosene was used and idle voltage $\mathrm{U}=60 \mathrm{~V}$ was applied.

The surfaces of machined samples were observed with use of scanning electron microscope at magnitude of $1000 \mathrm{x}$. The obtained photographs enabled to determine degree of recast layer removing. There were three cases distinguished (Fig. 2): A - grinding depth is bigger than recast layer thickness, B grinding depth is equal to recast layer thickness, C grinding depth is smaller than recast layer thickness. Only cases A and B have practical meaning. In case C the recast layer remains on the surface. This layer is usually not resistant to wear what decreases quality of surface layer. 


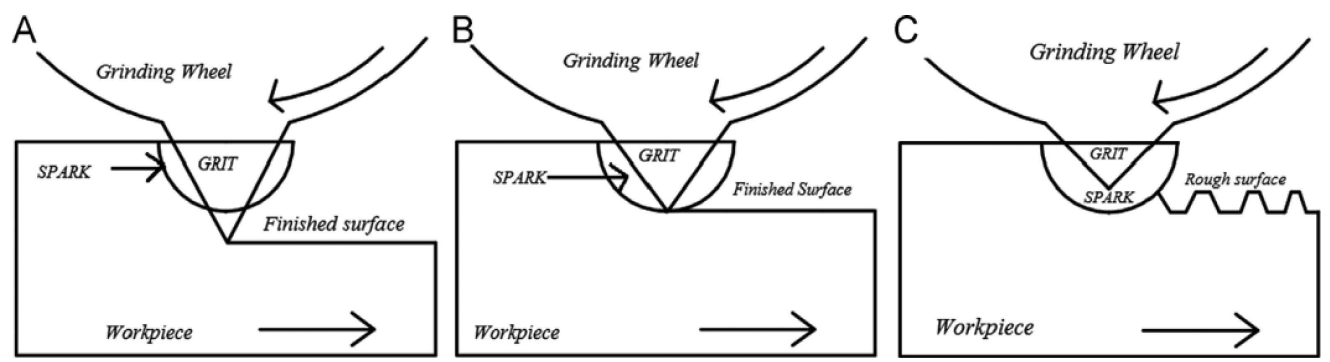

Fig. 2. Scheme of the grinding action at, (A) depth of cut is greater than crater radius, (B) depth of cut is equal to crater radius and $(\mathrm{C})$ depth of cut is less than crater radius [21].
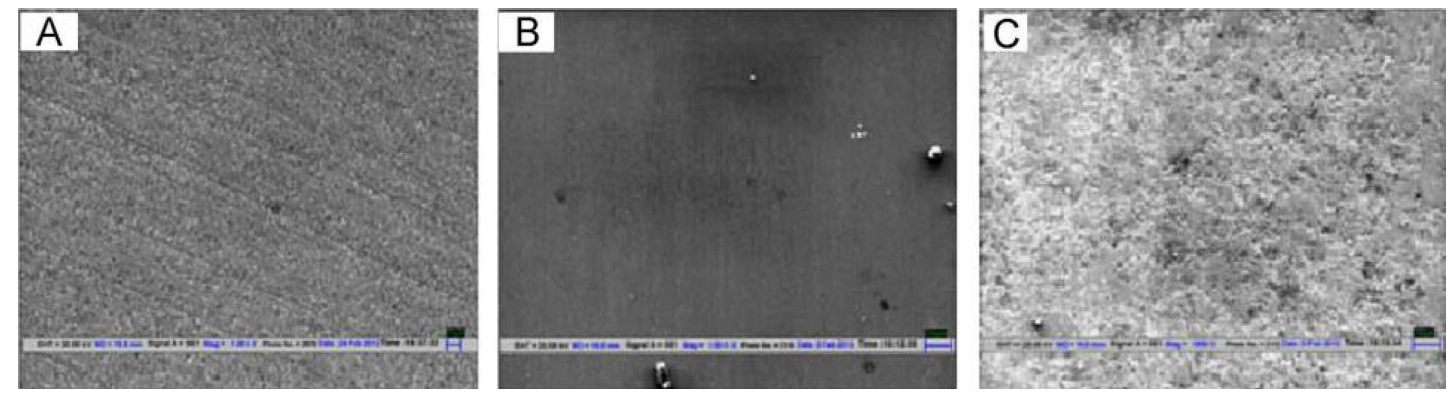

Fig. 3. SEM photography of $\mathrm{Al}_{2} \mathrm{O}_{3}-\mathrm{SiCw}-\mathrm{TiC}$ surface after AEDG [21]: A - surface when grinding depth was bigger than recast layer thickness $\left(V_{w}=4.9-8.8 \mathrm{mg} / \mathrm{min}, v_{p}=0.45-0.75 \mathrm{~m} / \mathrm{min}, V_{n}=1.57-3.14 \mathrm{~m} / \mathrm{min}, I=3-6\right.$ A, $\left.D=0.40-0.72, t_{\mathrm{on}}=100-300 \mu \mathrm{s}\right), \mathrm{B}-$ surface when grinding depth was equal to recast layer thickness $\left(V_{w}=8.1-\right.$ $\left.9.5 \mathrm{mg} / \mathrm{min}, v_{p}=0.45-0.90 \mathrm{~m} / \mathrm{min}, V_{n}=0.79-3.93 \mathrm{~m} / \mathrm{min}, I=4-5 \mathrm{~A}, D=0.40-0.56, t_{\mathrm{on}}=300-400 \mu \mathrm{s}\right), \mathrm{C}-$ surface when grinding depth was smaller than recast layer thickness $\left(V_{w}=6.9-14.1 \mathrm{mg} / \mathrm{min}, v_{p}=0.45-0.7 \mathrm{~m} / \mathrm{min}\right.$, $\left.v_{n}=1.57-3.14 \mathrm{~m} / \mathrm{min}, I=4-6 \mathrm{~A}, D=0.40-0.77, t_{\mathrm{on}}=300-400 \mu \mathrm{s}\right)$.

If on the surface of the machined material grinding traces are present, it can be a result of removing not only recast layer but also base material (Fig. 3A). If on the surface of the machined material there are no grinding traces or irregularities, it can be a result of removing recast layer only (Fig. 3B). It is a confirmation that the layer thickness was constant. If on the surface of the machined material one can spot recast layer and craters, it can be a result of removing not whole recast layer (Fig. 3C). In this case surface layer is similar to the EDM machined (Fig. 4). In the study the authors worked out models and made calculations for every of above described cases for grinding process efficiency, for EDM and AEDG. Resulting efficiency (AEDG) was calculated as weighted sum of EDM and grinding efficiency. The weighs were selected upon process conditions of all three described cases where three different surface morphologies can be distinguished. Distinction was made upon $\mathrm{F}$ indicator:

$$
F=I \cdot t_{\text {on }} \cdot D c=I \cdot \frac{t_{\mathrm{on}}^{2}}{t_{\mathrm{on}}+t_{\mathrm{off}}},
$$

where $I$ is discharge current amplitude, $t_{\mathrm{on}}-$ pulse on time, $t_{\text {off }}-$ pulse off time, $D c=\left(t_{\text {on }}\right) /\left(t_{\text {on }}+t_{\text {off }}\right)$ - duty factor.

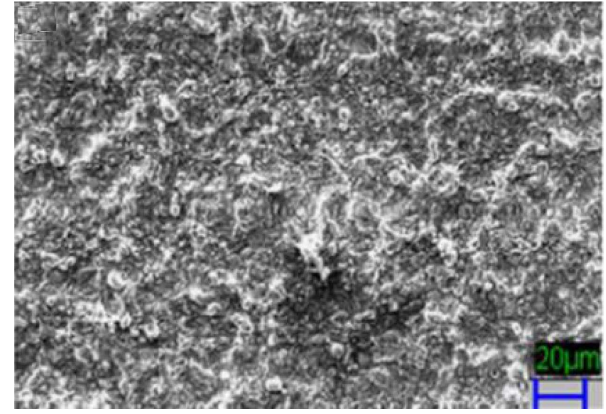

Fig. 4. SEM photography of the electro discharge machined $\mathrm{Al}_{2} \mathrm{O}_{3}-\mathrm{SiCw}-\mathrm{TiC}$ surface [21].

The proposed mathematical model for machining efficiency of AEDG process, assuming that the allowance is removed by means of electro discharges and grinding, was empirically verified. Calculated values differ from the measured by $2.75 \%$ only. The model enables also to select machining set of parameters to get surface topography according to variant $\mathrm{A}, \mathrm{B}$ or $\mathrm{C}$.

The cases can be distinguished upon $\mathrm{F}$ indicator. Obtained results indicate that for $F>900 \mathrm{EDM}$ process is dominant (there is recast layer on the top surface after machining), for $600<\mathrm{F}<900$ AEDG is dominant (whole recast is removed), and for $F<600$ 
grinding process is dominant (whole recast layer and base material is removed). The results predicted from the mathematical model valid in described above three cases were compared to empirical results. The maximum difference between modelling results and empirical one was $2.75 \%$. It confirms the model convergence to real conditions. It was also concluded that depending on process parameters its efficiency varies between $4.9-14.1 \mathrm{mg} / \mathrm{min}$. Considering that machined material hardness was $2400 \mathrm{HV}$ it makes AEDG process very efficient.

The surface morphology was qualitatively evaluated based upon scanning electron microscope images, but no quantitative evaluation was presented. These photographs (Fig. 3) enable classification of A, B and C type surface groups.

\section{AEDG of metal matrix composite materials (MMCs)}

Published results of empirical research on AEDG indicate efficiency of AEDG process in machining of high mechanical resistivity alloys as well as technical ceramics and $\mathrm{Al}$ based MMCs i.e. whisker$\mathrm{SiCp}$ snd $\mathrm{SiCp} / \mathrm{A} 356, \mathrm{SiC} / \mathrm{Al}$ and based on $\mathrm{Cu}-\mathrm{Fe}-\mathrm{C}$ (graphite).

Detailed research on MMCs $\mathrm{Cu}(60 \%)$ - Fe (30\%) - $\mathrm{C}(10 \%)$ machining were presented in [22]. The research was taking into account following parameters: electrical current (2-6 A), pulse on time (10-30 $\mu \mathrm{s})$, pulse off time $(15-25 \mu \mathrm{s})$ and granularity (80-240). As a tool the bronze based diamond grinding wheels with abrasive concentration $75 \%$ were used. Machining removal rate was varying in range from 0.4 to $0.12 \mathrm{~g} / \mathrm{min}$ and 3D roughness indicator SR from 0.84 to $1.93 \mu \mathrm{m}$.

Results of sintered carbide $[(86 \%) \mathrm{WC}$ (2.5\%)TiC-(6\%)TaNb)C-(5.5\%)CO] AEDG research [24] confirm that depending on conditions impact of EDM and grinding process on allowance removal changes. It determines composition and geometrical structure of the surface after machining. The composition and geometrical structure change significantly with current amplitude changes in AEDG (Fig. 5) for electrical current amplitude $\sim 0.4$ A some abrasive grain traces are visible on the machined surface, so whole recast layer and some thickness of base material was removed. For current amplitude $\sim 2.1$ A there are no abrasive grain traces and the machined surface is similar to the surface after EDM. The results show that machining efficiency increases in relation to classic grinding $\left(\sim 8 \mathrm{~mm}^{3} / \mathrm{min}\right)$ to $\sim 16 \mathrm{~mm}^{3} / \mathrm{min}$ for electrical current amplitude $(I-0.5 \mathrm{~A})$. For higher amplitude values process efficiency decreases and for $I=\sim 2 \mathrm{~A}$ it is lower than this for classic grinding.

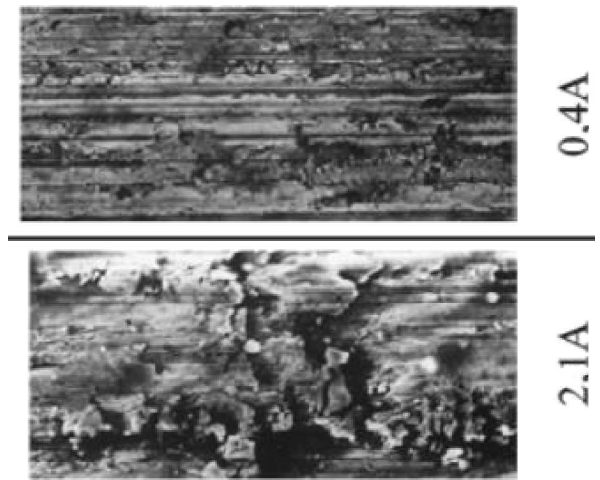

Fig. 5. [WC-TiC-(TaNb)C-Co] surface for $I=0.4$ A (recast layer totally removed, visible grinding traces) and $I=2.1$ A (recast layer not totally removed, EDM-like surface). For both cases pulse on time was $10 \mu \mathrm{s}$, duty factor 0.5 , grinding speed $4.7 \mathrm{~m} / \mathrm{s}$ [24].

\section{Abrasive wire electrodischarge machining (AWEDM)}

Despite of high potential the wire EDM is not widely applied for machining of high rotation speed aviation parts. The reason is lowered fatigue resistivity of the surface layer (recast layer occurs). In order to improve surface layer properties WEDM with use of diamond-metal wire was proposed [23]. The wire is common use tool for precise semiconductor cutting with diameter of $180 \mu \mathrm{m}$ (steel core and nickel bond diamond grains of $50 \mu \mathrm{m}$ coating). The research was carried out for SAE 1018 steel and nickel alloys (Nickel 600) in order to check recast layer presence (the recast layer presence is unacceptable on moving parts for aviation industry). In case of WEDM $5 \mu \mathrm{m}$ thick recast layer was present. For the same parameters set in AWEDM the recast layer was not present.

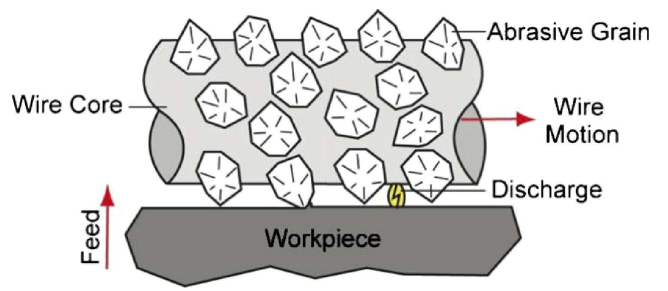

Fig. 6. Scheme of machining area in AWEDM [23].

The research presented in [23] was carried for the following set of parameters: $U$ up to $180 \mathrm{~V}$ (optimum $U$ in range of $108-162 \mathrm{~V}), t_{i}=4.9 \mu \mathrm{s}, t_{o}=100 \mu \mathrm{s}$, wire tension $6.8 \mathrm{~N}$ and wire speed $5.5 \mathrm{~m} / \mathrm{min}$. In these conditions cutting process material removal rate was $0.02-0.10 \mathrm{~mm}^{3} / \mathrm{min}$ and gap thickness was 8-20 $\mu \mathrm{m}$. In WEDM the same wire was applied 
as in AWEDM but with no abrasive grains. Figure 7 presents percentage process efficiency growth in AWEDM (in relation to WEDM). Efficiency increases with voltage and current amplitude decreasing. Further efficiency increase is possible due to wire speed increasing.

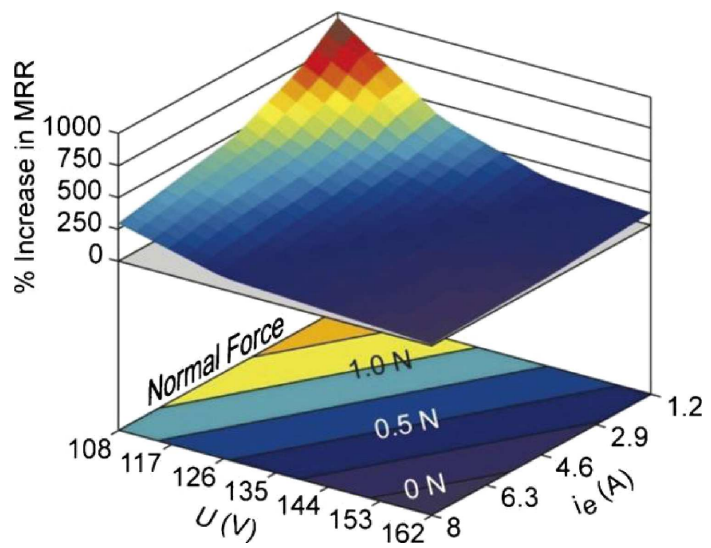

Fig. 7. MRR (material removal rate) and wire force change depending on interelectrode gap voltage $U$ and electrical current amplitude $i_{e}$ [23].

WEDM and AWEDM processes course can be also described with the use of machining product analyzing. These products for $U=162 \mathrm{~V}$ and $I=8 \mathrm{~A}$ contain characteristic for EDM solidified material. It can be confirmed by negligible AWEDM efficiency increase and no force applied to the wire. Machining products for $U=108 \mathrm{~V}$ and $I=8 \mathrm{~A}$ are in majority typical for abrasive machining what is confirmed in $300 \%$ efficiency increase and $1 \mathrm{~N}$ force applied to the wire (Fig. 7). Appearance of these products indicates also that the material before removing was seriously heated.

Presented in Fig. 8 photography shows surface topography after WEDM (a) and AWEDM ( $U=$ $108 \mathrm{~V}, I=8$ A) (b). Surface roughness Ra after WEDM process was $2 \mu \mathrm{m}$. The surface is isotropic and some micro cracks marked by arrows are noticeable. Whereas surface roughness Ra after AWEDM was $0.9 \mu \mathrm{m}$ and appeared typical for abrasive machining structure.

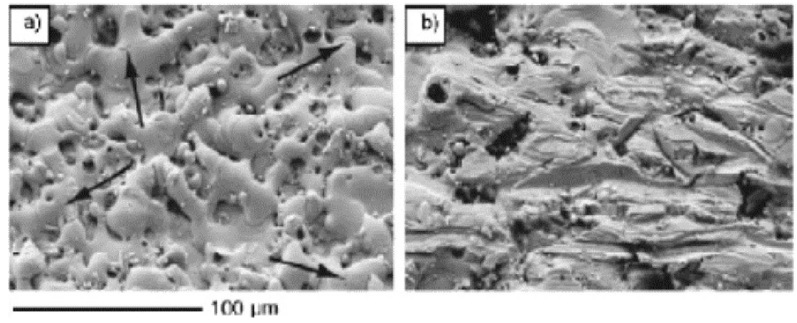

Fig. 8. Machined steel SAE 1018 surface photography: a) after WEDM and b) after (AWEDM) [23].
AWEDM research was also carried out for nickel alloy (Ni 600) (Fig. 9). Results show that after WEDM cutting the $5 \mu \mathrm{m}$ recast layer was present. After AWEDM cutting there was no recast layer or it occurs residually. Parts where top layer was recast free have proper strength and can be applied in moving aviation elements. Common use bronze core nickel-diamond grain plated wire was applied in the research. Typically this kind of wire is used for semiconductor cutting. Observations of the wire surface before and after machining revealed that after just few passes there was no abrasive diamond grains on the surface. Due to high temperature of EDM process diamond grains were destroyed by graphitization. Therefore from economical as well technology point of view for application in production $\mathrm{Al}_{2} \mathrm{O}_{3}$ abrasive grains are recommended.
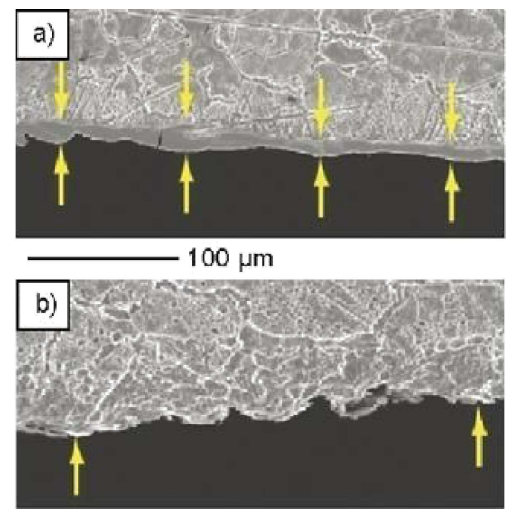

Fig. 9. Photography of machined surface ((Ni 600)nickel alloy) after WEDM (a) and AWEDM (b) process [23].

Moreover, for industrial application only use of wires partially covered with abrasive grain is reasonable. The part of wire free of abrasive grains could be used for precise positioning and power supply. Wire move direction should be perpendicular to abrasive grain covered part of the wire. Application of not circular cross section wire is also possible. It would make system positioning and driving easier. It is important as impact of abrasive process requires higher forces for moving the wire through machining area. In other words, industrial application of AWEDM requires refinement of the test stand used in the research as well as of technological tooling.

\section{Abrasive Electrochemical Machining (AECM)}

Previous research of electrochemically assisted grinding (AECG) revealed important differences in relation to classic process $[20,25,26]$. The most important of them are that in AECG energy consump- 
tion, grinding forces values and tool wear were lower when efficiency and surface quality were significantly improved. Especially in case of sintered carbides, high strength alloys (Inconel, Nimonic), titanium alloys, nickel alloys and metal matrix composite (PCD - $\mathrm{Co}, \mathrm{Al}$. - SiC, $\mathrm{Al}_{-} \mathrm{Al}_{2} \mathrm{O}_{3}$ ) machining. Depending on machining regime surface quality that can be reached was even $\mathrm{Ra} \ll 0.1 \mu \mathrm{m}$.

\section{Finishing electrochemical grinding after electro discharge machining}

Titanium alloys are widely applied in aviation, automotive and medical industry thanks to their high corrosion resistance. However machining of Ti$6 \mathrm{Al}-4 \mathrm{~V}$ is difficult because of low thermal conductivity, chemical activity and low value of Young modulus. Conventional machining processes do not assure the quality of the machined surface required by aviation industry. Electro discharge machining is a common method of material shaping. After EDM surface layer is hard and brittle and some craters (with melted in products of erosion) resulting from electrical discharge are visible. Surface roughness Ra varies between $2.69 \mu \mathrm{m}$ (for $I=3 \mathrm{~A}$ ) up to $5.79 \mu \mathrm{m}$ (for $I=25 \mathrm{~A}$ ). Some micro cracks diminishing surface quality can be also observed. Recast layer presence on the surface disqualifies such parts for application in many sectors of aviation industry.

Similar conclusions as for nickel alloy machining can be drawn for titanium alloys which are commonly used in aviation, automotive and medical industry due to high corrosion resistivity. Machining of such alloys is difficult due to their low thermal conductivity, chemical reactivity and low value of plasticity module. Conventional machining processes cannot provide required machining quality together with acceptable efficiency. That explains application of unconventional methods like EDM. However after electro discharge machining recast layer and craters as well as melted in erosion products on the part surface are present. Due to these artefacts surface roughness is high: $2.19 \mu \mathrm{m}$ (for $I=3 \mathrm{~A}$ ) and $5.79 \mu \mathrm{m}$ (for $I=25 \mathrm{~A})$.
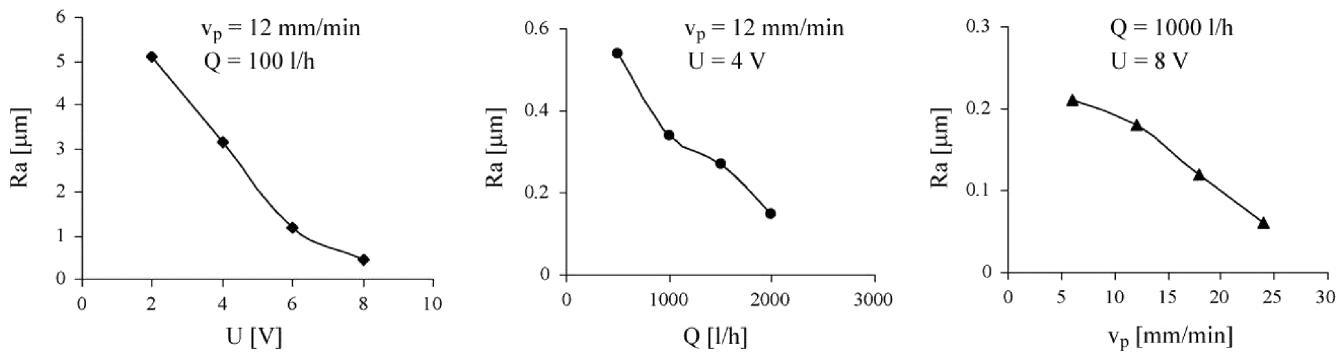

Fig. 11. Impact of working voltage $U$, electrolyte flow rate $Q$ and working table feed rate $v_{p}$ changes on surface
Properly selected conditions of electrodischarge - abrasive finishing machining could significantly improve machining process. However abrasive electrodischarge grinding, due to mechanical and thermal allowance removal mechanism, has some limitations connected with surface quality, e.g. in EDG process of MMCs $\mathrm{Cu}(60 \%)-\mathrm{Fe}(30)-\mathrm{C}(10 \%)$ based it is possible to obtain roughness $\mathrm{SR} \sim 0.84-1.93 \mu \mathrm{m}$. AEDG enables SAE 1018 steel surface quality $\mathrm{Ra}=$ $0.9 \mu \mathrm{m}$.

Therefore the surface of the EDM machined parts should to be improved. In order to decrease surface roughness electrochemical grinding can be applied. For example, EDM rough machining of titanium alloy (Ti-6Al-4V) was finished by electrochemical grinding (Fig. 10) [3]. As a tool copper based grinding wheel EC BOND A100V4CD of $350 \mathrm{~mm}$ diameter and width $70 \mathrm{~mm}$ was applied. Electrochemical grinding tests were carried for following machining conditions $U=2-8 \mathrm{~V}$, feed rate: $6-24 \mathrm{~mm} / \mathrm{min}$, electrolyte $\mathrm{NaNO}_{3}$ concentration $180 \mathrm{~g} / \mathrm{l}$.

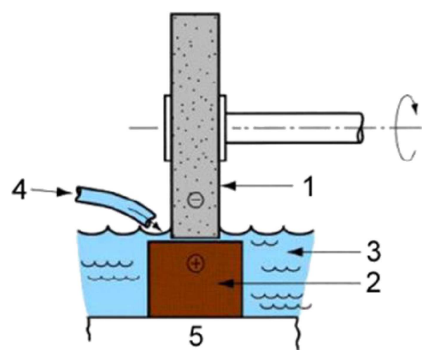
grinding wheel, 2 - workpiece, 3 - electrolyte, 4 - electrolyte inlet, 5 - working table [3].

The electrolyte was delivered to the machined area at the following flow rate: $500-2000 \mathrm{l} / \mathrm{h}$. Grinding depth was higher than recast layer thickness and was $50 \mu \mathrm{m}$. As a consequence of electrochemical grinding recast layer was removed and surface roughness Ra was decreased up to $0.06 \mu \mathrm{m}$ (Fig. 11), what is impossible to obtain by AEDG process. This value is satisfactory for aviation industry demands.
Fig. 10. Scheme of AECG process: 1 - metal bonded

\footnotetext{
roughness Ra in ECG process of Ti-6Al-4V alloy [3].
} 


\section{Shape electrochemical grinding}

An important limit to practical application of conventional grinding process by grinding tools of small dimensions is their fast wear. Effective application of small grinding tools is possible in electrochemical grinding process, where grinding tool wear is much lower than during conventional grinding process (due to much smaller cutting forces). Extensive and insightful research revealed possibility of practical application of electrochemical grinding by small cylindrical or spherical grinding tools build of metal matrix and diamond or c-BN grains [e.g. 25, 26]. Similar idea is presented in [27]. Small grinding tools were applied for machining of nickel based alloys used in aviation industry. These alloys were machined with use of shaped grinding tools of various diameter with the range from 10 to $15 \mathrm{~mm}$ [27]. Grinding tools were applied for finishing of shaped blade mounting slots in flow engine turbine rings. Machining of such blade mounting slots is a serious challenge for several leading aircraft engine producers. Research in this area is focused on finding an alternative for broaching blade mounting slots finishing process. The most common processes for rough machining are traditional milling and abrasive water jet machining (AWJC) as well as electro discharge wire machining (WEDM). Depending on accuracy and shape of initially obtained slots the next finishing operation can be electrochemical machining with use of a shaped grinding tool. Depending on accuracy and shape of primary prepared gaps the next finishing operation can be electrochemical machining assisted by a shaped grinding wheel (Figs. 12 and 13). During finishing operation the grinder was flushed by electrolyte from two nozzles. The best results were achieved for finishing by grinders made by means of electrochemical deposition (electroplated) with cBN (B151) grains and spindle rotation $2000 \mathrm{rpm}$. That resulted in grinding ratio $11-15 \mathrm{~m} / \mathrm{s}$. Mean depth of grinding was $0.92 \mathrm{~mm}$ and obtained roughness $\mathrm{Ra}=0.65 \mu \mathrm{m}$.
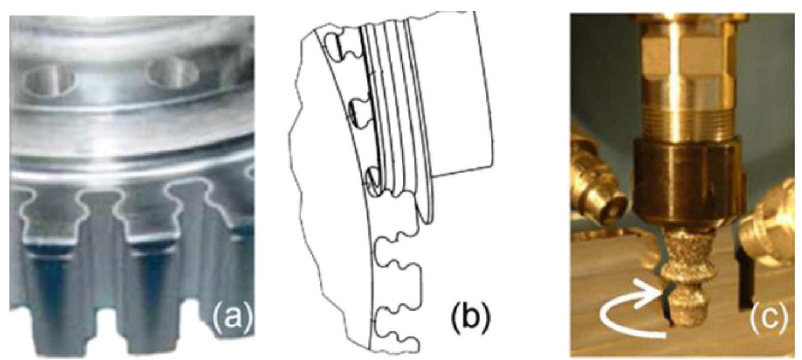

Fig. 12. (a) Abrasive water jet cutting of blade mounting slots, (b) slot classical grinding using cup wheel and (c) point electrochemical grinding of slot [27].
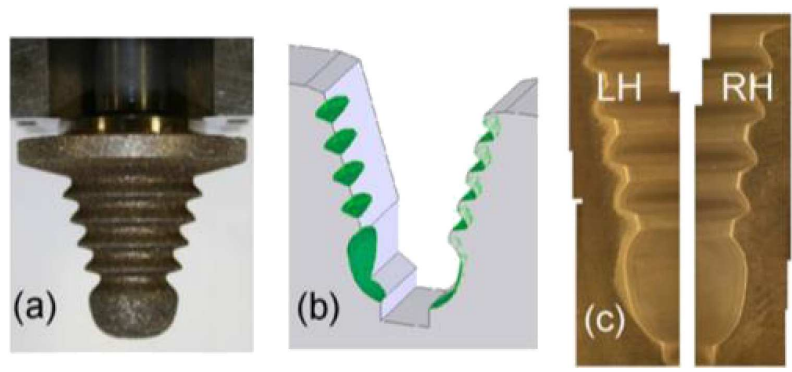

Fig. 13. (a) Electroplated cBN "fir tree" grinding point, (b) CAD model of contact area and (c) slot entry [27].

\section{Finishing machining of gear wheels}

In order to ensure high quality of gears it is necessary to pay extra attention on accuracy of the sprocket preparation, the material, lubrication and the quality of sprocket teeth quality that depends on applied finishing operation. Shape error and surface roughness can be substantially decreased as a result of the common processes of grinding and reaching. Nevertheless both processes have some drawbacks. The grinding is expensive, complicated and can cause burs of the tooth surface what seriously decreases gear quality. On the other hand, reaching ensures good quality of the surface but is time consuming and can introduce some tooth shape accuracy error.

In order to eliminate above mentioned disadvantages new hybrid process was proposed. The process was called by authors "electrochemical honing". It is obviously not a strict definition, because in this particular case there is no abrasive, so more proper name for this process would be "electrochemically assisted mechanical finishing" [28]. Fundamentals of finishing operation for bevel gear was presented in Fig. 14. Machined wheel $(1)$, cathode wheel $(3,4)$ and honing wheel (2) were prepared by Gleason method. Cathode wheels 3 and 4 were coupled to machined part in areas made of isolating material. There is ca. $1 \mathrm{~mm}$ gap between conical cathode wheels made of copper and machined wheel where the electrolyte is flushed by nozzles. After switching on electrical power and coupled wheels drive the surface of machined wheel is covered by passive layer. In the meantime machined wheel (1) couples tightly honing wheel (2) not connected to the power supply. Machined wheel (1) and tool wheel (2) were made of hardened alloy steel 20MnCr5. Hardness of machined wheel was 50-54 HRC and honing wheel (2) 58-62 HRC. This slight difference of hardness assisted by tight coupling of the wheels is enough to remove passive layer from the machined wheel. 


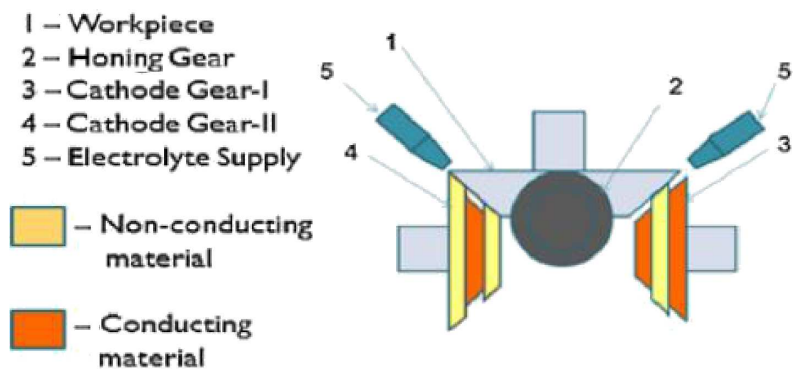

Fig. 14. Proposed working principle for finishing of bevel wheels [28].

During this research electrolytes were a composition of $\mathrm{NaNO}_{3}(75 \%)$ and $\mathrm{NaCl}(25 \%)$ and concentration in water solution of $5-10 \%$ were applied. The electrolyte temperature varied from 27 to $37^{\circ} \mathrm{C}$, the flow rate from 10 to $40 \mathrm{l} / \mathrm{min}$. Machined wheel rotation speed varied from 40 to $80 \mathrm{rpm}$ and inter electrode voltage $U$ was changed in range of 8 to $16 \mathrm{~V}$. During these tests no machining wheel wear was observed. After 2 minutes of coupling of wheels 1 and 2 mean value of $\mathrm{Ra}$ for machined wheel decreased from 1.79 to 1.09 and $R_{\max }$ from 10 to $8.42 \mu \mathrm{m}$. Decreasing of Ra has positive impact on gear wear and produced noise, whereas decreasing $R_{\max }$ improved gear lifetime. For 2 min. work time optimal parameter set was voltage $U=12 \mathrm{~V}$ and $60 \mathrm{rpm}$. Increasing machining time reduces positive effects.

\section{Conclusions}

Aviation, aerospace, medical and military industry demand advanced materials (like ceramics $\mathrm{Al}_{2} \mathrm{O}_{3}$-SiCw-TiC), sintered carbides (i.e. [WCTiC-(TaNb)C-Co]), titanium alloys, nickel alloys (i.e.Nickel 600) and metal matrix based composites (i.e. $\mathrm{Cu}(60 \%)-\mathrm{Fe}(30)-\mathrm{C}(10 \%))$. These materials are difficult to shape even by unconventional methods. In particular, it is difficult to reach satisfactory efficiency of the machining process together with proper part surface quality that would be acceptable for practical applications. In finishing operations satisfactory results can be obtained by application of AEDG and AWEDM. Regardless, due to thermal and mechanical character of the allowance removal it is difficult to reach surface quality $\mathrm{SR} \ll 1 \mu \mathrm{m}$. Smaller values of surface roughness can be reached by application of electrochemical grinding.

Combination of allowance removal by electrical discharge or electrochemical dissolution and abrasive grinding enables:

- increasing of machining efficiency in relation to classical EDM and mechanical grinding,
- reaching satisfactory properties of surface layer and geometrical structure of surface,

- decreasing abrasive grain wear and increasing of the grinding wheel lifetime by decreasing forces applied to abrasive grains,

- grinding wheel self-sharpening phenomena (previously described in this paper)

- decreasing friction intensity between machined material and grinding wheel bond that decreases grinding process temperature.

Capabilities of abrasive hybrid manufacturing processes outlined in the paper show potential of these methods when machining difficult-to-cut materials. In justified cases their application in manufacturing process chain is connected with a number of economic reasons i.e. increased efficiency, increased tool lifetime and reduction of post processing costs. It is worth to underline that recent developments in abrasive hybrid manufacturing processes meet also high industrial demands and challenges regarding geometrical precision and surface integrity. Therefore, correct technology management in this area allows to overcome limitations of existing solution and opens up new opportunities for manufacturing chain.

\section{References}

[1] Lauwers B. et al., Hybrid processes in Manufacturing, CIRP Annals - Manufacturing Technology, 63, 561-583, 2014.

[2] Lauwers B., Surface Integrity in Hybrid Machining Processes, Procedia Engineering, 19, 241-251, 2011.

[3] Hascalik A., Cydas U., A comparative study of surface integrity of Ti-6Al-4 V Alloy machined by EDM and $A E C G$, Journal of Materials Processing Technology, 190, 173-180, 2007.

[4] Skoczypiec S., Ruszaj A., A sequential electrochemical - electrodischarge process for microparts manufacturing, Precision Engineering, 38, 3, 680-690, July 2014.

[5] Liang Z., Wu Y., Wang X., Zhao W., A New TwoDimensional Ultrasonic Assisted Grinding Method and Its Fundamental Performance in Monocrystal Silicon Machining, International Journal of Machine Tools \& Manufacture, 50, 728-736, 2010.

[6] Klocke F. et al., Abrasive machining of advanced aerospace alloys and composites, CIRP Annals Manufacturing Technology, 64, 581-604, 2015.

[7] Zhao B., Wu Y.G., Jiao G.F., Research on micro-mechanism of nanocomposite ceramic in twodimensional ultrasound grinding, Key Engineering Materials, 304, 344-348, 2008. 
[8] Bhaduri D. et al., A study on ultrasonic assisted creep feed grinding of Nickel based superalloys, Procedia CIRP, 1, 359-364, 2012.

[9] Gao G.F. et al., Research on the surface characteristics in ultrasonic grinding nano-zirconia ceramics, Journal of Materials Processing Technology, 209, 32-37, 2009.

[10] Ghahramani M. et al., Ultrasonic-Assisted Grinding of Ti6A14V Alloy, Procedia CIRP, 1, 353-358, 2012 .

[11] Liang Z. et al., Experimental study on brittle-ductile transition in elliptical ultrasonic assisted grinding (EUAG) of monocrystalline sapphire using single abrasive grain, Journal of Materials Processing Technology, 71, 41-51, 2013.

[12] Mohsen G.N., Movahhedy M.R., Javad A., Ultrasonic-Assisted Grinding of Ti6Al4V Alloy, Procedia CIRP, 1, 353-358, 2012.

[13] Yildiz Y., Nalbandt M., A review of cryogenic cooling in machining processes, International Journal of Machine Tools \& Manufacture, 48, 947-964, 2008.

[14] Manimaran G., Kumar M.P., Effect OF cryogenic cooling and sol-gel alumina Wheel on grinding performance of AISI 316 stainless steel, Archives of Civil and Mechanical Engineering, 13, 304-312, 2013.

[15] Manimaran G. et al., Influence of cryogenic cooling $l$ on surface grinding of stainless steel 316, Cryogenics, 59, 76-83, 2014.

[16] Ichida Y. et al., Material removal mechanism in non contact ultrasonic abrasive machining, Wear, 258, 107-114, 2005.

[17] Chen Y.F., Lin Y.Ch., Surface modification of Al$Z n-M g$ alloy using combined EDM with ultrasonic machining and addition of $\mathrm{TiC}$ particles into dielectric, Journal of Materials Processing Technology, 209, 4343-4350, 2009

[18] Prihandana G.S., et al., Effect of micro-powder suspension and ultrasonic vibration of dielectric fluid in micro-EDM process - Taguchi approach, Inter- national Journal of Machine Tools \& Manufacture, 49, 1035-1041, 2009.

[19] Wong Y.S. et al., Near-mirror phenomenon in EDM using powder-mixed dielectric, Journal of Materials Processing Technology, 79, 30-40, 1998.

[20] Kozak J., Oczoś K.E., Selected problems of abrasive hybrid machining, Journal of Materials Processing Technology, 109, 360-366, 2001.

[21] Satyarthi M.K., Pandey P.M., Modelling of material removal rate in electric discharge grinding process, International Journal of Machine Tools \& Manufacture, 74, 65-73, 2013.

[22] Shrivastava P.K, Dubey A.K., Experimental modeling and optimization of electric discharge diamond face grinding of metal matrix composite, International Journal of Advanced Manufacturing Technology, 69, 2471-2480, 2013.

[23] Menesis I., Koshy P., Assessment of abrasion assisted material removal in wire EDM, CIRP Annals Manufacturing Technology, 57, 195-198, 2008.

[24] Koshy P., Jain G.K., Lal G.K., Grinding of cemented carbide with electrical spark assistance, Journal of Materials Processing Technology, 72, 61-68, 1997.

[25] Ruszaj A. et al., The Investigations Aiming to Increase the Flexibility of Electrochemical Grinding, International Journal of Electrical Machining, 3, 2532, January 1998

[26] Ruszaj A. et al., Investigations aiming at working out the CAD/CAM system for electrochemical grinding with spherical abrasive tool, International Journal of Electrical Machining, 5, 35-40, January 2000 .

[27] Curtis D.T. et al., Electrochemical superabrasive machining of a nickel - based aero engine alloy using mounted grinding points, CIRP Annals - Manufacturing Technology, 58, 173-179, 2009.

[28] Shaikh J.H., Jain N.K., Modelling of material removal rate and surface roughness in finishing of bevel gears by electrochemical honing process, Journal of Materials Processing Technology, 214, 200-209, 2014. 